\title{
Educación sanitaria e hiperfosforemia: resultados a 1 año de un programa de intervención enfermera
}

\author{
Ana Vanessa Fernández Martínez, María Ruiz Serna, Rosario Pérez García, Yania Arregui Arias, Francisco \\ Rodríguez Martínez, Rocío Pérez Díaz
}

\section{Fresenius Medical Care Services Cartagena y San Pedro del Pinatar. Murcia}

\section{Introducción:}

Evitar la hiperfosfatemia en el paciente en hemodiálisis tiene como objetivos conseguir un adecuado control del metabolismo óseo-mineral y reducir el riesgo cardiovascular y la alta tasa de morbimortalidad de estos pacientes. El objetivo del presente estudio fue evaluar el impacto de la intervención enfermera en los conocimientos del paciente sobre el fósforo y sus complicaciones, nutrición y fósforo, en el cumplimiento terapéutico y en los niveles séricos de fósforo tras un año desde su aplicación.

\section{Material y método:}

Se diseña un estudio prospectivo sobre población prevalente en hemodiálisis (HD). Se reclutan 117 pacientes, $90,1 \%$ de los pacientes en hemodiafiltración on-line. Tiempo efectivo semanal superior a 720 minutos de diálisis. Previa a intervención (P1), a los 4 meses (P2) y al año (P3) se realiza una encuesta de valoración sobre el grado de conocimientos del paciente acerca del fósforo (definición, sintomatología asociada y valores analíticos normales y anormales), medicación usada para su control y forma de tomarla, número de fármacos que refiere tomar y prescritos, conocimiento general sobre alimentación y fósforo, así como 10 preguntas de mayor o menor dificultad, comparando cual de dos alimentos contiene más fósforo a su criterio. La intervención en todos los pacientes consistió en al menos tres charlas guiadas con documentación escrita. En aquellos pacientes con altos niveles de fósforo, incumplimiento terapéutico y/o dificultad para la comprensión se realizaron tutorías. El análisis estadístico se realiza mediante SPSS 13.0 para Windows. Se estima significación estadística para una $p<0,05$.

\section{Resultados:}

Los niveles de fósforo se reducen de forma significativa ( $p=0,006): 4,11(1,29) \mathrm{P} 1,3,74(1,02) \mathrm{P} 2$, $3,54(1,69) \mathrm{P} 3$. así como el \% de pacientes con fósforo>5 mg/dl (23,9\% P1, 14,5\% P2, 15,4\% P3).

Frente al $36,8 \%$ de pacientes que tomaba correctamente el tratamiento previo a la intervención, el $64,1 \%$ lo hace a los 4 meses y al año $(p<0,001)$, aumentando significativamente $(p=0,040)$ los fármacos que toman $(0,77$ y $0,76 \mathrm{P} 2$ y $\mathrm{P} 3$ versus $0,55 \mathrm{P} 1)$, con descenso no significativo de la medicación prescrita (1,45 P1, 1,22 P2 y 1,34 P3).

Se constata una mejoría significativa en conocimientos: generales $(p<0,001) 52,1 \% \mathrm{Pl}, 75,2 \%$ $P 2,71,8 \% P 3$, síntomas relacionados $(p<0,001)$ $54,7 \% \mathrm{P} 1,74,1 \% \mathrm{P} 2,71,8 \% \mathrm{P} 3$, niveles normales $(p=0,005) 43,6 \% P 1,64,9 \%$ P2, 54,7\% P3, medicación relacionada $(p=0,003) 52,1 \% \mathrm{P} 1,75,2 \% \mathrm{P} 2$, $74,8 \%$ P3 y dieta $(p<0,001) 54,7 \% \mathrm{P} 1,80,3 \% \mathrm{P} 2$, $70,9 \%$ P3.

\section{Conclusiones:}

La implantación de un plan de salud con intervenciones regladas de la enfermería nefrológica mejora el cumplimiento terapéutico, así como el conocimiento general del paciente sobre el fósforo, su tratamiento y la dieta. Del mismo modo, se constata una reducción del fósforo sérico, una menor prescripción de quelantes, una mayor adhesión al tratamiento y una disminución del \% de pacientes con hiper- 
fosforemia, por lo que la intervención enfermera es altamente eficiente en el manejo de la fosforemia. Estos resultados se mantienen en el tiempo.

\section{Referencias Bibliográficas}

1. Torregrosa JV, Bover J, Cannata J y cols. Recomendaciones de la Sociedad Española de Nefrología para el manejo de la enfermedad ósea-mineral en el paciente con enfermedad renal crónica. Nefrología 2011, 31 (Suppl 1): 3-32.

2. Rodríguez-Benot $A$, Martín-Malo A, Álvarez Lara $M A$, y cols. Mild Hyperphosphataemia and mortality in hemodiálisis patients. Am J Kidney Dis 2006, 46 (1): 66-77.

3. Palmer SC. Serum levels of phosphorus, parathyroide hormone and calcium and risk of death and cardiovascular disease in individuals with chronic kidney disease. A sistematyc review and meta-analysis. JAMA 2011, 905 (11): 11191127.

4. National Kidney Foundation: K/DOQI Clinical Practice Guidelines for bone metabolism and disease in chronic kidney disease. Am J Kidney Dis 2003; 4: 21-201.

5. Moe SM, Drüeke TB, Block GA, y cols. KDIGO clinical practice guideline for the diagnosis, evaluation, prevention, and treatment of Chronic Kidney Disease-Mineral and Bone Disorder (CKD-MBD) Kidney Disease: Improving Global Outcomes (KDIG0) CKD-MBD Work Group Kidney Int Suppl. 2009; (113):S1-130.

6. De Francisco ALM. ¿Debemos considerar el costoefectividad de los distintos tratamientos al aplicar las recomendaciones sobre los captores (quelantes) del fósforo? Nefrología 2008, 28 (2): 129-134.

7. Roca S, de Alarcón RM, Jimeno y cols. Coste farmacéutico en el paciente en hemodiálisis. Componentes principales y repercusión en el coste global. Nefrología 2011, 31 (Suppl 2): 118.

8. Arenas MD, Malek T, Álvarez-Ude F, y cols. Captores del fósforo: preferencias de los pacientes en hemodiálisis y su repercusión sobre el cumplimiento del tratamiento y el control del fósforo. Nefrología, 2010, 30 (3): 522-530.

9. Fernández $A V$, Arregui $Y$, Piñero J, y cols. Coste farmacéutico, adherencia terapéutica y educación sanitaria: un reto para la enfermería nefrológica en la próxima década. Libro de Comunicaciones presentadas al XXXVI Congreso de la SEDEN. Sevilla 2011.

10. Impacto de la aplicacion de un plan de salud sobre el conocimiento del paciente, cumplimentacion terapeutica y niveles de fósforo en una población en hemodiálisis. Libro de comunicadas presentadas al XXXVII Congreso de la SEDEN. Ávila 2012.

11. Tattersall J, Martin-Malo A, Pedrini, y cols. EBPG guideline on dialysis strategies. Nephrol Dial Transplant (2007) 22 [Suppl 2]: 5-21

12. Maduell F. Convección versus difusión. ¿Ha llegado el momento del cambio? Nefrología 2009, 29 (6): 589-593.

13. National Kidney Foundation: K/DOQI Clinical Practice Guidelines for nutrition in chronic renal failure. Am J Kidney Dis 2000; 35 (Suppl2): S1-S140.

14. Muro B, Pernaut J y Urzainqui P. Control del metabolismo del fósforo en la consulta prediálisis. Disponible en: www.revistaseden.org/files/1967-13(2).pdf.

15. Manzano JM, Nieto MD, Sánchez MC. Valoración nutricional de enfermería de los pacientes tratados con hemodiálisis en un centro periférico. Rev Soc Enferm Nefrol 2004; 7 (1): 10-18

16. Ochando A, Royuela $C$, Hernández ME y cols. Influencia de la satisfacción de los pacientes de una unidad de diálisis en la adherencia terapéutica. Rev Soc Enferm Nefrol 2008; 11 (4): 271-276

17. Mariana C, Puigvert C, García ML. Valoración de un programa de educación sanitaria a pacientes con insuficiencia renal crónica. Rev Soc Esp Enferm Nefrol 2002 (5): 4: 14-17

18. Andrés MM, Gruss E, Marín J y cols. Nivel de conocimiento de los pacientes en hemodiálisis sobre conceptos básicos relacionados con su enfermedad y tratamiento. Disponible en www.revistaseden. org/files/2008-80(2).pdf. 